\title{
The Severe 5\%: A Latent Class Analysis of the Externalizing Behavior Spectrum in the United States
}

\author{
Michael G. Vaughn ${ }^{\text {a,* }}$, Matt DeLisi ${ }^{\text {b }}$, Tracy Gunter ${ }^{a}$, Qiang Fu ${ }^{\text {a }}$, Kevin M. Beaver ${ }^{\mathrm{c}}$, \\ Brian E. Perron ${ }^{\mathrm{d}}$, Matthew O. Howard ${ }^{\mathrm{e}}$ \\ a Saint Louis University, United States \\ b Iowa State University, United States \\ c Florida State University, United States \\ d University of Michigan, United States \\ e University of North Carolina at Chapel Hill, United States
}

\section{A R T I C L E I N F O}

Available online 13 January 2011

\begin{abstract}
A B S T R A C T
Objective: Criminological research consistently demonstrates that approximately $5 \%$ of study populations are comprised of pathological offenders who account for a preponderance of antisocial behavior and violent crime. Unfortunately, there have been no nationally representative epidemiological studies characterizing the severe $5 \%$ group.

Materials and Methods: Data from the 2001-2002 National Epidemiologic Survey on Alcohol and Related Conditions (NESARC), a nationally representative sample of 43,093 non-institutionalized U.S. residents aged 18 years and older were analyzed using latent class analysis to assess sociodemographic, psychiatric, and behavioral characteristics.

Results: Four-classes of respondents were identified vis-à-vis lifetime externalizing behaviors. A normative class ( $66.1 \%$ of respondents) demonstrated little involvement in antisocial conduct. A low substance use/high antisocial behavior class ( $20.7 \%$ of respondents) and high substance use/moderate antisocial behavior ( $8.0 \%$ of respondents) class evinced diverse externalizing and psychiatric symptoms. Finally, a severe class (5.3\% of respondents) was characterized by pathological involvement in more varied and intensive forms of antisocial and externalizing behaviors and extensive psychiatric disturbance.

Conclusions: The current study is the first nationally representative epidemiological study of criminal careers/ externalizing behavior spectrum in the United States and validates the existence of the $5 \%$ pathological group demonstrated by prior research.
\end{abstract}

(C) 2010 Elsevier Ltd. All rights reserved.

\section{Introduction}

The empirical finding that approximately $5 \%$ of a sample or population is constituted by pathological offenders has been so frequently documented that it is nearly axiomatic. Across social and behavioral science literatures and spanning a range of constructs, including life-course-persistent offenders, serious, violent, and chronic delinquents, psychopaths, and career criminals, this $5 \%$ group is characterized by a disproportionate contribution to crime and related social problems, by a sharply disproportionate contribution to serious violence, by evidence of life-long psychopathology, and by the imposition of extreme social burden and other collateral costs (DeLisi,

\footnotetext{
is Author's Note: NESARC was funded by the National Institute on Alcohol Abuse and Alcoholism with additional support provided by the National Institute on Drug Abuse. The authors are grateful for support from NIH grants: DA021405 (Dr. Howard) and K07CA104119 (Dr. Fu). The authors report no conflicts of interest.

* Corresponding author.

E-mail address: mvaughn9@slu.edu (M.G. Vaughn).
}

2005; Hodgins, Viding, \& Plodowski, 2009; Moffitt, 1993; Salekin \& Lynam, 2010; Vaughn \& DeLisi, 2008). Indeed, this group has been identified as the most pressing and important problem in pediatric mental health (Eme, 2010), and studies indicate that individual offenders can produce millions of dollars in justice system, victimization, and related costs (Cohen, 1998; Cohen \& Piquero, 2009; DeLisi \& Gatling, 2003; DeLisi, Kosloski, Sween, Hachmeister, Moore, \& Drury, 2010). For these reasons, better understanding of the causes and correlates of pathological antisocial behavior are central to prevention, treatment, and criminal justice interventions.

Although a large literature has documented the social and offending histories of this cadre of severe offenders, there are important methodological limitations of this prior work. First, birth cohort designs (e.g., Brame, Mazerolle, \& Piquero, 2010; Gomez-Smith \& Piquero, 2005; Piquero \& Buka, 2002; Piquero \& White, 2003; Wolfgang, Figlio, \& Sellin, 1972) are geographically circumscribed, and although relatively large in terms of sample size, are too small to produce a nationally representative profiles of this population. Second, many examinations of criminal careers and the small group of severe offenders among them 
were unfortunately based on data that contained too few pathological offenders (particularly those who commit murder and rape) (DeLisi, 2001; Piquero, Farrington, \& Blumstein, 2007). This led to a third, concomitant problem that centered on the use of relatively small, enriched samples of correctional clients, arrestees, civilly committed patients, and other defendants (Berg \& DeLisi, 2005; Harris, Smallbone, Dennison, \& Knight, 2009; Lussier, LeBlanc, \& Proulx, 2005; McCluskey, McCluskey, \& Bynum, 2006; Schroeder, Giordano, \& Cernkovich, 2010) or the use of inmate data to examine offending careers occurring in the community and even during confinement (Blackburn \& Trulson, 2010; Cunningham, Sorensen, Vigen, \& Woods, 2010; Roberts \& Wells, 2010). These conditions placed investigators in a bind in terms of securing data that were potentially generalizable to the broader universe of offenders while also enriched enough to contain pathological offenders. Characterizing the extremes of the externalizing spectrum as termed by research on problem behavior in the psychological and psychiatric sciences (Krueger Hicks, Patrick, Carlson, Iacono, \& McGue, 2002; Krueger, Markon, Patrick, \& Iacono, 2005) seems an important contribution to the criminological study of asymmetry in offending. And, although the criminal careers paradigm is a leading arena of research in criminology, there has not yet been a nationally representative, epidemiological study of externalizing antisocial behavior with particular focus on the pathological, severe $5 \%$ group. The current study fills this void.

\section{Methods}

\section{Participants}

Study findings are based on data from the 2001-2002 National Epidemiologic Survey on Alcohol and Related Conditions (NESARC). NESARC is a nationally representative sample of 43,093 noninstitutionalized U.S. residents aged 18 years and older (Grant et al., 2003). The survey gathered background data and extensive information about substance use and comorbid psychiatric disorders, including personality disorders, from individuals living in households and group settings such as shelters, college dormitories, and group homes in all 50 states and the District of Columbia. NESARC utilized a multistage cluster sampling design, oversampling young adults, Hispanics, and African-Americans in the interest of obtaining reliable statistical estimation in these subpopulations, and to ensure appropriate representation of racial/ethnic subgroups. The overall response rate was $81 \%$. Data were weighted at the individual and household levels to adjust for oversampling and non-response on demographic variables (i.e., age, race/ethnicity, sex, region, and place of residence). Data were also adjusted to be representative (based on region, age, race, and ethnicity) of the U.S. adult population as assessed during the 2000 Census. Study participants provided fully informed consent. The U.S. Census Bureau and the U.S. Office of Management and Budget approved the research protocol and informed consent procedures. Although developed for the epidemiological study of psychiatric conditions and substance use (Grant, Stinson, Dawson, Chou, Ruan, \& Pickering, 2004), the NESARC has increasingly been utilized to study an array of phenotypes in the epidemiology of antisocial and criminal behaviors (Goldstein, Grant, Ruan, Smith, \& Saha, 2006; Vaughn, Fu, Beaver, DeLisi, Perron, \& Howard, 2010; Vaughn, Fu, Bender, DeLisi, Beaver, Perron, \& Howard, 2010; Vaughn, Fu, DeLisi, Beaver, Perron, \& Howard, 2010; Vaughn, Fu, DeLisi, Beaver, Terrell, Perron, \& Howard, 2009; Vaughn, Fu, DeLisi, Wright, Beaver, Perron, \& Howard, 2010).

\section{Diagnostic assessment}

Data were collected through face-to-face structured psychiatric interviews conducted by U.S. Census workers trained by the National Institute on Alcohol Abuse and Alcoholism and U.S. Census Bureau. Interviewers administered the Alcohol Use Disorder and Associated Disabilities Interview Schedule - DSM-IV version (AUDADIS-IV), which provides diagnoses for mood, anxiety, personality, and substance use disorders (American Psychiatric Association, 2000). The AUDADIS IV demonstrates good-to-excellent reliability in assessing alcohol and drug use in the general population (Grant, Harford, Dawson, Chou, \& Pickering, 1995; Hasin, Carpenter, McCloud, Smith, \& Grant, 1997). Specific disorders included major depression, dysthymia, and bipolar disorder, social phobia, generalized anxiety disorder, panic disorder, specific phobia, and psychotic disorder. In addition to the assessment of psychiatric disorders a host of sociodemographic and background characteristics were also collected in these interviews. These included age, gender, race and ethnicity, income, education, marital status, and region of the country.

\section{Externalizing behaviors}

Externalizing behaviors were assessed using drug use and antisocial behavior items. Specifically, drug use items assessed lifetime use of hallucinogens, cocaine/crack, marijuana, stimulants, tranquilizers, and sedatives. Questions were worded as follows for drug use: Have you EVER used any of these medicines or drugs? The remaining thirty-three items were part of the conduct disorder and antisocial behavior interview module that all NESARC participants completed. Sample items included, “"In your ENTIRE LIFE, did you EVER have a time when you bullied or pushed people around or tried to make them afraid of you?" and "In your ENTIRE LIFE, did you EVER steal anything from someone or someplace when no one was around? The reliability of these items in test-retest analyses indicated adequate stability $(r=0.69)$ (Grant et al., 2003). The internal consistency reliability for the entire antisocial behavior criterion set was good ( $\alpha=.86$ ) (Blanco, Grant, Petry, Simpson, Alegria, Liu, \& Hasin, 2008) as was the convergent relations of items (Goldstein et al., 2006; Grant, Hasin, Stinson, Dawson, Chou, Ruan, \& Pickering, 2004).

\section{Statistical analyses}

The analytic objective was to model the latent structure of externalizing behaviors in the data. As such, the analyses proceeded in a number of interlocked steps. First, we examined the lifetime prevalence of each externalizing behavior and if it was less than $3 \%$ it was not used to identify latent structure as these items were endorsed by too few in the study sample and this would cause instability in model building. Next, a series of latent class models from 2 to 4 classes were carried out to identify distinct subtypes of externalizing respondents. The Bayesian Information Criterion (BIC) was used as one method to select the best-fitting model. A lower BIC value suggests the model with a better fit and parsimony. Log-likelihood values were used to assess model fit. Higher values reflect better model fit. In addition, we used entropy, a standardized measure of how accurately respondents are classified, to guide the selection of the final model. Higher values are preferred. The theoretical interpretability of various class solutions was also considered to aid in selection of the final model. Finally, we predicted class membership based on previously described sociodemographic and psychiatric covariates. Functionally, this is equivalent to a multinomial regression model that regresses the probability of class membership on each predictor variable in the models. Odds ratios and accompanying confidence intervals were estimated. The LCA and multinomial regression models were fit to the data simultaneously. The sampling weights that adjusted for the complex survey sampling design, probability of selection, and nonresponding were incorporated in the analysis. All analyses were conducted using MPlus 5.21 (Muthén \& Muthén, 2008).

\section{Results}

\section{Prevalence of externalizing behaviors}

The lifetime prevalence estimates for 34 externalizing behaviors in the entire sample $(\mathrm{N}=43,093)$ are shown in Fig. 1 . With respect to 


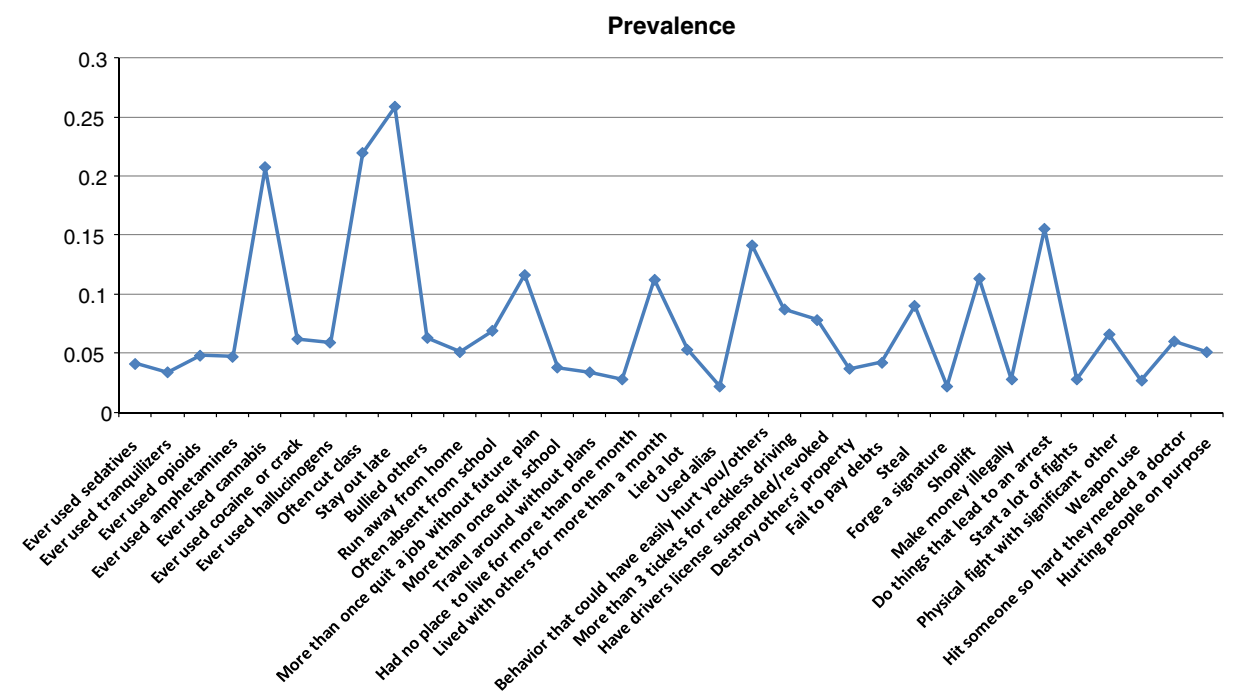

Fig. 1. Lifetime prevalence of 34 externalizing behaviors $(N=43,093)$.

drug use, prevalence estimates for non-medical use of sedatives, tranquilizers, opioids, and amphetamines were approximately $5 \%$. Lifetime prevalence estimates for powdered cocaine/crack and hallucinogen use were each approximately six percent. The lifetime prevalence of cannabis was much higher (20.6\%) than comparable figures for other drugs of abuse. There was substantially greater variance across antisocial behaviors. For example, prevalence figures for staying out too late (25.8\%) and cutting class (21.9\%) were significantly higher than other low base-rate antisocial behaviors such as use of an alias and traveling around without any plans, which were each reported by approximately three percent of respondents. Most antisocial behaviors were reported by $5 \%$ to $15 \%$ of respondents.

\section{Identification of latent classes}

Comparative statistics for class models suggest that the four-class solution was the best fitting model (see Figs. 2-5). BIC values were lower for the four-class model compared to the three-class model. With respect to purity of class assignment, entropy values indicated a small increase from the three-class model (86.6) to the four-class model (87.7). Inspection of the log-likelihood plot also suggested the four-class solution was optimal. An accelerated flattening of the curve indicated improved fit and that an additional class may not be parsimonious.

\section{Sensitivity analysis}

As a final validity check a sensitivity analysis was conducted in order to assess the stability of class membership. We assessed the effect of class stability for the four-class solution by plotting the

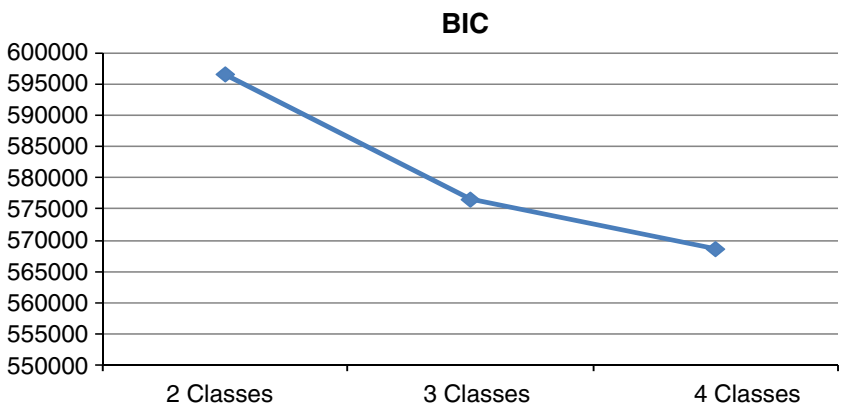

Fig. 2. BIC values across latent classes. membership curve across classes for solutions with and without covariates. Results of these procedures (See Fig. 6) indicated negligible differences between these models.

The final four-class solution is comprised of a normative class (66.0\%, $\mathrm{N}=28,442$ ), a low substance use/high antisocial behavior class $(20.7 \%, N=8,920)$, a high substance use/moderate antisocial class $(8.0 \%, \mathrm{~N}=3,447)$, and finally a severe class $(5.3 \%, \mathrm{~N}=2,284)$ characterized by high levels of both substance use and antisocial behavior.

Entropy

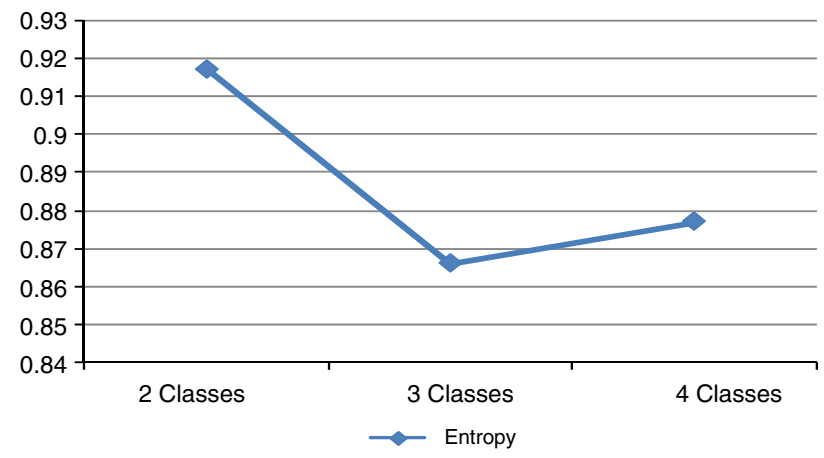

Fig. 3. Entropy values across latent classes.

\section{LogLikelihood}

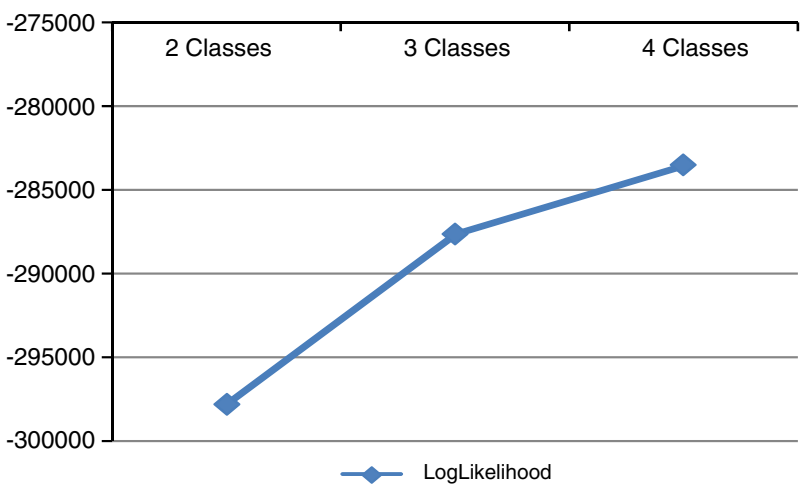

Fig. 4. Trends in log-likelihood values across latent classes. 


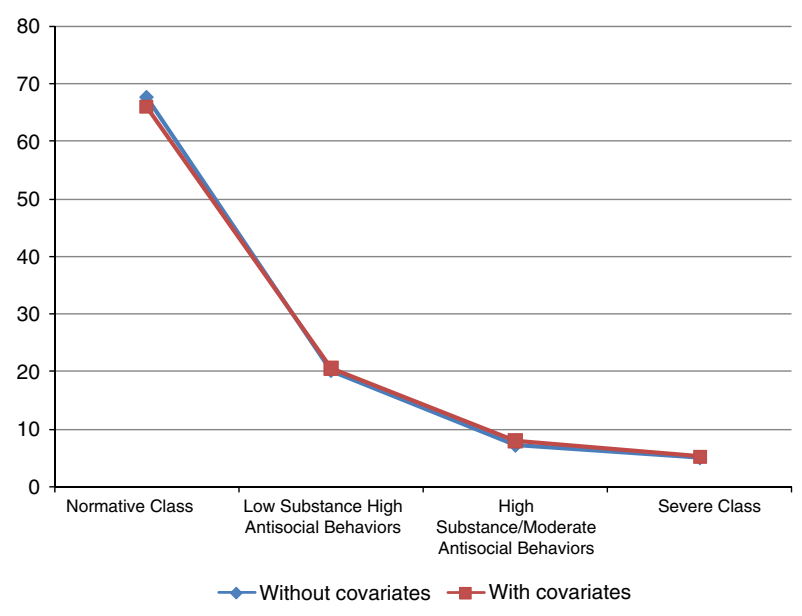

Fig. 5. Probability of four latent classes with and without covariates.

\section{Demographic and mental health characteristics of latent classes}

Table 1 displays the sociodemographic and mental health characteristics of the three offender latent classes compared to the reference normative class. With respect to race/ethnicity, African-Americans were $87 \%$ less likely to be members of the high substance use/moderate antisocial behavior class and 36\% less likely to be members of the severe class compared to Whites. Hispanics were less likely than Whites to be a member of any of the three externalizing classes. Unmarried status was uniformly predictive of all three externalizing behaviors classes. Persons who were divorced were at $61 \%$ increased odds compared to married persons of being a member of the high substance use/moderate antisocial behavior and severe classes. Compared to the lowest levels of income ( $<\$ 19,999$ annual income), those in the $\$ 20,000$ to $\$ 34,999$ annual income category were at increased odds of being a member in the severe class but persons in this same income category were also less likely to be members of the high substance use/moderate antisocial behavior class. Having less than a high school diploma $(\mathrm{OR}=2.42, \mathrm{CI}=1.93-3.04)$ and completion of high school $(\mathrm{OR}=1.56, \mathrm{CI}=1.34-1.83)$ were predictive of membership in the severe class. This pattern was also true for the low substance use/high antisocial behavior class but not the high substance use/moderate antisocial behavior class. In terms of region of the country, persons from the West were uniformly at increased odds compared to the South of being members of all three externalizing classes.

All mental health disorder covariates except for generalized anxiety disorder were predictive of membership in all three externalizing classes. However, effects were strongest for the severe class. For example, large effects were found for bipolar disorder $(\mathrm{OR}=7.89$, $\mathrm{CI}=6.37-9.76)$ and psychotic disorder $(\mathrm{OR}=6.00, \mathrm{CI}=3.52-10.23)$, which were approximately twice as predictive of membership in the severe class than other classes.

\section{Discussion}

Nearly 40 years ago, Wolfgang et al. (1972) produced the seminal finding that a small group of adolescents-6\% in the 1945 Philadelphia birth cohort-contributed mightily to the incidence of crime and violence in the cohort of nearly 10,000 boys. The empirical regularity of this finding has influenced subsequent theory and research and figured prominently in the fields of child and adolescent psychiatry, criminology, juvenile justice, and criminal justice. Indeed, Moffitt (2003, pp. 49-50, references omitted) stated, "The taxonomy of childhood-onset versus adolescent-onset antisocial behavior has been codified in the DSM-IV, invoked in the National Institute of Mental Health Child and Adolescent Violence Research and the U.S. Surgeon General's report Youth Violence, and presented in abnormal psychology and criminology textbooks." In other words, it is increasingly recognized that a relatively small pathological group exists, and this group will manifest problem behaviors early in life, engage in versatile and serious forms of maladaptive and criminal behaviors, and persist in antisocial behaviors long after more normative delinquents have desisted from crime. The current study adds to the convergent validity of the "severe 5\%" hypothesis drawing on data from more than 43,000 respondents from the 2001-2002 National Epidemiologic Survey on Alcohol and Related Conditions (NESARC).

The latent classes demonstrate the heterogeneity in the externalizing spectrum. Nearly two-thirds of respondents were normative in

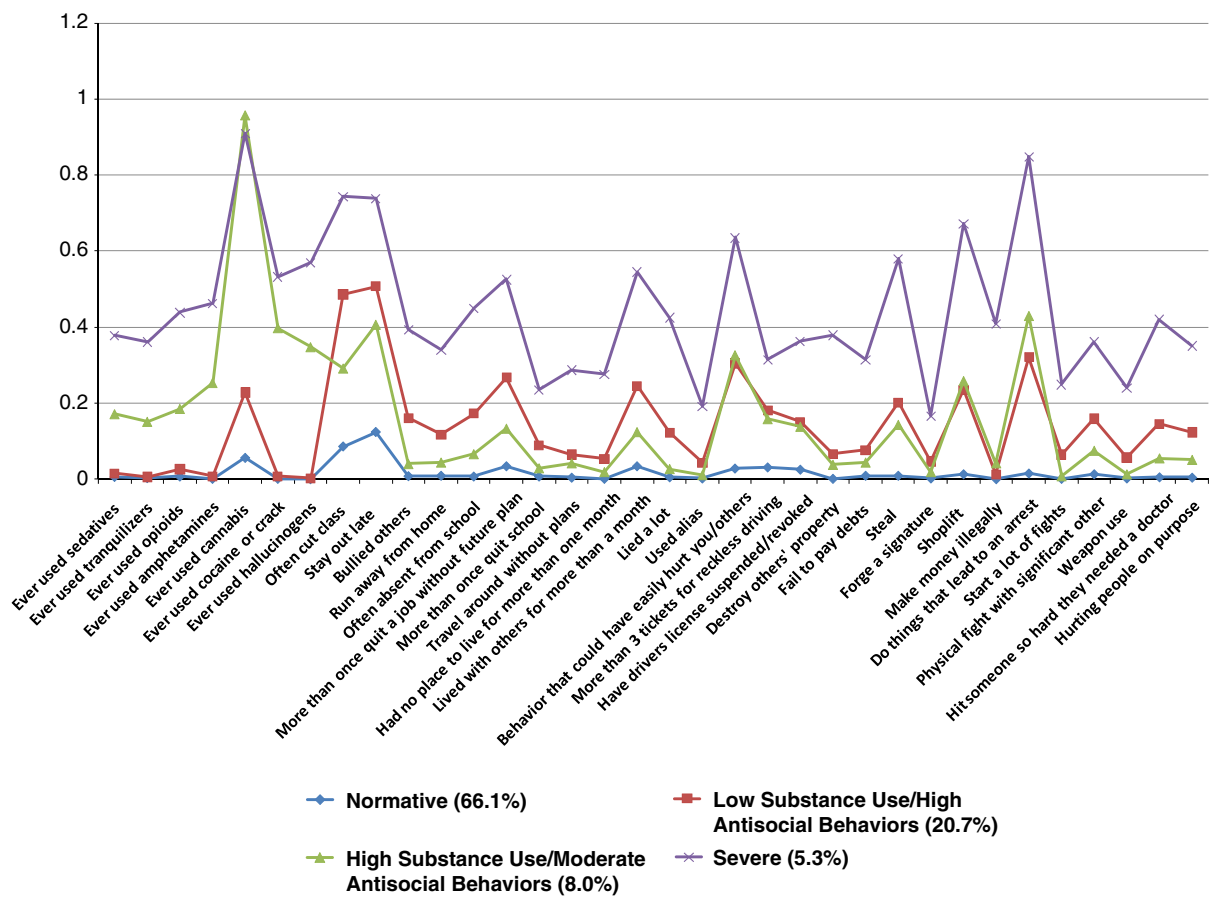

Fig. 6. Lifetime prevalences of 34 externalizing behaviors across 4 latent classes. 
Table 1

Sociodemographic characteristics and psychiatric comorbidity of externalizing spectrum latent classes

\begin{tabular}{|c|c|c|c|}
\hline Variables & $\begin{array}{l}\text { Class } 2 \\
\text { (Low substance use/high antisocial) } \\
\text { OR }(95 \% \mathrm{CI})\end{array}$ & $\begin{array}{l}\text { Class } 3 \\
\text { (High substance use/moderate antisocial) } \\
\text { OR }(95 \% \mathrm{CI})\end{array}$ & $\begin{array}{l}\text { Class } 4 \\
\text { (Severe) } \\
\text { OR }(95 \% \mathrm{CI})\end{array}$ \\
\hline Age $18-34$ & $5.64(4.75-6.68)$ & $44.08(25.12-77.36)$ & $137.00(58.63-320.12)$ \\
\hline Age $35-49$ & $3.70(3.11-4.40)$ & $49.85(28.18-88.18)$ & $104.17(43.72-248.21)$ \\
\hline Age $50-64$ & $2.72(2.34-3.16)$ & $16.18(9.02-29.02)$ & $31.60(13.26-75.29)$ \\
\hline \multicolumn{4}{|l|}{ Race/ethnicity } \\
\hline African-American & $1.01(0.90-1.13)$ & $0.13(0.25-0.39)$ & $0.64(0.52-0.79)$ \\
\hline Hispanic & $0.54(0.46-0.63)$ & $0.34(0.28-0.41)$ & $0.30(0.23-0.40)$ \\
\hline Other & $0.53(0.43-0.66)$ & $0.30(0.22-0.41)$ & $0.71(0.49-1.02)$ \\
\hline \multicolumn{4}{|l|}{ Annual Income } \\
\hline$\$ 20,000-34,000$ & $1.02(0.89-1.18)$ & $0.61(0.49-0.76)$ & $1.33(1.03-1.70)$ \\
\hline$\$ 35,000-69,000$ & $1.05(0.92-1.21)$ & $0.68(0.55-0.84)$ & $1.30(1.04-1.63)$ \\
\hline$\$ 70,000$ - above & $1.02(0.90-1.14)$ & $0.73(0.63-0.85)$ & $1.08(0.87-1.33)$ \\
\hline Unmarried & $1.12(1.0-1.24)$ & $1.37(1.18-1.58)$ & $1.24(1.06-1.44)$ \\
\hline Divorced & $1.08(0.97-1.20)$ & $1.61(1.34-1.93)$ & $1.61(1.36-1.91)$ \\
\hline \multicolumn{4}{|l|}{ Education } \\
\hline Less than high school & 1.63(1.44-1.85) & $0.53(0.39-0.72)$ & $2.42(1.93-3.04)$ \\
\hline High school & $1.18(1.07-1.30)$ & $0.66(0.57-0.76)$ & $1.56(1.34-1.83)$ \\
\hline \multicolumn{4}{|l|}{ Region } \\
\hline Northeast & $0.95(0.79-1.14)$ & $1.23(1.01-1.51)$ & $1.01(0.79-1.29)$ \\
\hline Midwest & $1.49(1.20-1.75)$ & $1.02(0.85-1.22)$ & $1.38(1.06-1.78)$ \\
\hline West & $1.44(1.16-1.79)$ & $2.09(1.69-2.59)$ & $2.41(1.79-3.23)$ \\
\hline Lifetime mood disorder & $2.08(1.86-2.33)$ & $1.67(1.43-1.96)$ & $2.58(2.17-3.06)$ \\
\hline Bipolar disorder & $3.94(3.28-4.72)$ & $1.78(1.36-2.32)$ & $7.89(6.37-9.76)$ \\
\hline Dysthymia & $1.48(1.22-1.79)$ & $1.64(1.24-2.17)$ & $2.28(1.80-2.89)$ \\
\hline Panic disorder & $1.69(1.40-2.05)$ & $1.71(1.34-2.19)$ & $2.15(1.67-2.76)$ \\
\hline Social phobia & $1.93(1.60-2.32)$ & $1.71(1.31-2.23)$ & $2.06(1.64-2.59)$ \\
\hline Specific phobia & $1.56(1.37-1.77)$ & $1.40(1.17-1.69)$ & $2.35(1.93-2.86)$ \\
\hline Generalized anxiety disorder & $1.22(0.98-1.52)$ & $1.13(0.83-1.52)$ & $1.26(0.96-1.66)$ \\
\hline Psychotic disorder & $3.42(2.03-5.78)$ & $2.92(1.47-5.78)$ & $6.00(3.52-10.23)$ \\
\hline
\end{tabular}

Reference $=$ class one (normative class).

that they demonstrated little involvement in problem and criminal behaviors and little psychiatric comorbidity. Interestingly, the $66.1 \%$ prevalence of the normative class is consistent with the normative, crime-free group from the seminal 1945 Philadelphia birth cohort (Wolfgang et al., 1972). One in five adults in the NESARC demonstrated high externalizing behaviors coupled with low substance use. Compared to the normative class, this group was nearly four times more likely to have Bipolar Disorder and 3.4 times as likely to have a Psychotic Disorder. A smaller class constituted by $8 \%$ of the NESARC respondents had moderate antisocial conduct coupled with high substance abuse. The severe $5 \%$ class displayed high levels of virtually all types of externalizing behaviors (see Fig. 6) that are consistent with the career criminal, life-course-persistent offender prototype that exists in the criminological literature. An added dimension to this group is their broad psychiatric comorbidity. Compared to the normative class which served as a control group, the severe 5\% presented with significantly higher odds of having all forms of psychiatric disorder with the exception of Generalized Anxiety Disorder. Although only $5 \%$ of the sample, in practical terms this means that on average there is a child in every classroom that is part of this subset.

Although the size and epidemiological scope of the NESARC are unsurpassed by criminal careers datasets, there are important limitations of the current effort that we hope can inform future epidemiological studies of offending careers over the life course. These data were cross-sectional and prevented not only an assessment of the temporal relationships between variables, but also a temporal look at the unfolding of these externalizing careers. For instance, there were no data on the onset of externalizing, delinquent, or criminal behaviors which is a cardinal feature of severe offenders. Although it is understood that onset is inversely related to criminal career severity (DeLisi, Beaver, Wright, \& Vaughn, 2008; McCluskey et al., 2006), it is also the case that some serious offenders do not begin offending until adulthood (Eggleston \& Laub, 2002; Gomez-Smith \&
Piquero, 2005). To illustrate, a study of adult career criminals with a minimum arrest criterion of 30 arrests discovered that $25 \%$ were not first arrested until age 21 or older (DeLisi, 2006). Moreover, because NESARC was designed to focus on alcohol use, substance use, and related psychiatric conditions, there were not explicit measures of common parameters of criminal careers research, such as arrests, court appearance, probation violations, and related criminal justice system contacts. Future research, for example, could investigate the symptom measures within some of the psychiatric diagnoses, such as Antisocial Personality Disorder, to create secondary measures of criminal justice system contacts.

In the end, the current study provides comprehensive empirical validation to what has long been recognized; namely, that a small subset of individuals is pathological in their externalizing and antisocial conduct. As future research investigates the "severe 5\%" to better understand its etiology, developmental course, and consequences, it is our hope that prevention modalities are developed to preclude the severity from manifesting. We believe that severe antisociality and related psychopathic syndromes represents a public health issue of enormous proportions that go beyond the generic youth violence focus of the Centers on Disease Control and Prevention. Developing a stronger system of prevention science for this subset is critically needed.

\section{References}

American Psychiatric Association. (2000). Diagnostic and statistical manual of mental disorders, Fourth edition, Text revision. Washington, DC: Author.

Berg, M. T., \& DeLisi, M. (2005). Do career criminals exist in rural America? Journal of Criminal Justice, 33, 317-325.

Blackburn, A. G., \& Trulson, C. R. (2010). Sugar and spice and everything nice? Exploring institutional misconduct among serious and violent female delinquents. Journal of Criminal Justice. doi:10.1016/j.jcrimjus.2010.09.001.

Blanco, C., Grant, J., Petry, N. M., Simpson, H. B., Alegria, A., Liu, S. -M., \& Hasin, D. (2008). Prevalence and correlates of shoplifting in the United States: Results from the National Epidemiologic Survey on Alcohol and Related Conditions (NESARC). American Journal of Psychiatry, 165, 905-913. 
Brame, R., Mazerolle, P., \& Piquero, A. R. (2010). Criminal career progression among serious youthful offenders in Australia. Journal of Criminal Justice, 38, 340-347.

Cohen, M. A. (1998). The monetary value of saving a high-risk youth. Journal of Quantitative Criminology, 14, 5-33.

Cohen, M. A., \& Piquero, A. R. (2009). New evidence on the monetary value of saving a high- risk youth. Journal of Quantitative Criminology, 25, 25-49.

Cunningham, M. D., Sorensen, J. R., Vigen, M. P., \& Woods, S. O. (2010). Inmate homicides: Killers, victims, motives, and circumstances. Journal of Criminal Justice, $38,348-358$

DeLisi, M. (2001). Extreme career criminals. American Journal of Criminal Justice, 25, $239-252$.

DeLisi, M. (2005). Career criminals in society. Thousand Oaks, CA: Sage.

DeLisi, M. (2006). Zeroing in on early arrest onset: Results from a population of extreme career criminals. Journal of Criminal Justice, 34, 17-26.

DeLisi, M., Beaver, K. M., Wright, J. P., \& Vaughn, M. G. (2008). The etiology of criminal onset: The enduring salience of nature and nurture. Journal of Criminal Justice, 36, $217-223$.

DeLisi, M., \& Gatling, J. M. (2003). Who pays for a life of crime? An empirical assessment of the assorted victimization costs posed by career criminals. Criminal Justice Studies, 16, 283-293.

DeLisi, M., Kosloski, A., Sween, M., Hachmeister, E., Moore, M., \& Drury, A. (2010). Murder by numbers: Monetary costs imposed by a sample of homicide offenders. The Journal of Forensic Psychiatry \& Psychology, 21, 501-513.

Eggleston, E. P., \& Laub, J. H. (2002). The onset of adult offending: A neglected dimension of the criminal career. Journal of Criminal Justice, 30, 603-622.

Eme, R. (2010). Male life-course-persistent antisocial behavior: The most important pediatric mental health problem. Archives of Pediatrics and Adolescent Medicine, 164, $486-487$.

Goldstein, R. B., Grant, B. F., Ruan, W. J., Smith, S. M., \& Saha, T. D. (2006). Antisocial personality disorder with childhood- vs. adolescence-onset conduct disorder: Results from the National Epidemiologic Survey on Alcohol and Related Conditions. Journal of Nervous and Mental Disorders, 194, 667-675.

Gomez-Smith, Z., \& Piquero, A. R. (2005). An examination of adult onset offending. Journal of Criminal Justice, 33, 515-525.

Grant, B. F., Dawson, D. A., Stinson, F. S., Chou, P. S., Kay, W., \& Pickering, R. P. (2003). The Alcohol Use Disorder and Associated Disabilities Interview Schedule-IV (AUDADIS- IV): Reliability of alcohol consumption, tobacco use, family history of depression and psychiatric diagnostic modules in a general population sample. Drug and Alcohol Dependence, $71,7-16$.

Grant, B. F., Harford, T., Dawson, D. A., Chou, P. S., \& Pickering, R. P. (1995). The Alcohol Use Disorder and Associated Disabilities Interview schedule (AUDADIS): Reliability of alcohol and drug modules in a general population sample. Drug and Alcohol Dependence, 39, 37-44.

Grant, B. F., Hasin, D., Stinson, F. S., Dawson, D. A., Chou, S. P., Ruan, W. J., \& Pickering, R. P. (2004). Prevalence, correlates, and disability of personality disorders in the United States: Results from the National Epidemiologic Survey of Alcohol and Related Conditions. Journal of Clinical Psychiatry, 65, 948-958.

Grant, B. F., Stinson, F. S., Dawson, D. A., Chou, S. P., Ruan, W. J., \& Pickering, R. P. (2004). Co-occurrence of 12-month alcohol and drug use disorders and personality disorders in the United States: Results from the National Epidemiologic Survey on Alcohol and Related Conditions. Archives of General Psychiatry, 61, 361-368.

Harris, D. A., Smallbone, S., Dennison, S., \& Knight, R. A. (2009). Specialization and versatility in sexual offenders referred for civil commitment. Journal of Criminal Justice, 37, 37-44.

Hasin, D., Carpenter, K. M., McCloud, S., Smith, M., \& Grant, B. F. (1997). The alcohol use disorders and associated disabilities interview schedule (AUDADIS): Reliability of alcohol and drug modules in a clinical sample. Drug and Alcohol Dependence, 44, $133-141$.

Hodgins, S., Viding, E., \& Plodowski, A. (Eds.). (2009). The neurobiological basis of violence: Science and rehabilitation. New York: Oxford University Press.
Krueger, R. F., Hicks, B. M., Patrick, C. J., Carlson, S. R., Iacono, W. G., \& McGue, M. (2002) Etiologic connections among substance dependence, antisocial behavior, and personality: Modeling the externalizing spectrum. Journal of Abnormal Psychology $111,411-424$.

Krueger, R. F., Markon, K. E., Patrick, C. J., \& Iacono, W. G. (2005). Externalizing psychopathology in adulthood: A dimensional spectrum conceptualization and its implications for DSM-V. Journal of Abnormal Psychology, 114, 537-550.

Lussier, P. LeBlanc, M., \& Proulx, J. (2005). The generality of criminal behavior: A confirmatory factor analysis of the criminal activity of sex offenders. Journal of Criminal Justice, 33, 177-189.

McCluskey, C. P., McCluskey, J. D., \& Bynum, T. S. (2006). Early onset offending and later violent and gun outcomes in a contemporary youth cohort. Journal of Criminal Justice, 34, 531-541.

Moffitt, T. E. (1993). Adolescence-limited and life-course-persistent antisocial behavior: A developmental taxonomy. Psychological Review, 100, 674-701.

Moffitt, T. E. (2003). Life-course-persistent and adolescence-limited antisocial behavior: A 10- year research review and a research agenda. In B. B. Lahey, T. E. Moffitt, \& A. Caspi (Eds.), Causes of conduct disorder and juvenile delinquency (pp. 49-75). New York: The Guilford Press.

Muthén, L., \& Muthén, B. O. (2008). Mplus user's guide (5th ed.). Los Angeles: Muthén \& Muthén.

Piquero, A. R., \& Buka, S. L. (2002). Linking juvenile and adult patterns of criminal activity in the Providence cohort of the National Collaborative Perinatal Project. Journal of Criminal Justice, 30, 259-272.

Piquero, A. R., Farrington, D. P., \& Blumstein, A. (2007). Key issues in criminal career research: New analyses of the Cambridge Study in Delinquent Development. New York: Cambridge University Press.

Piquero, A. R., \& White, N. A. (2003). On the relationship between cognitive abilities and life- course-persistent offending among a sample of African Americans: A longitudinal test of Moffitt's hypothesis. Journal of Criminal Justice, 31, 399-409.

Roberts, J., \& Wells, W. (2010). The validity of criminal justice contacts reported by inmates: A comparison of self-reported data with official prison records. Journal of Criminal Justice, 38, 1031-1037.

Salekin, R. T., \& Lynam, D. R. (Eds.). (2010). Handbook of child and adolescent psychopathy. New York: The Guilford Press.

Schroeder, R. D., Giordano, P. C., \& Cernkovich, S. A. (2010). Adult child-parent bonds and life course criminality. Journal of Criminal Justice, 38, 562-571.

Vaughn, M. G., \& DeLisi, M. (2008). Were Wolfgang's chronic offenders psychopaths? On the convergent validity between psychopathy and career criminality. Journal of Criminal Justice, 36, 33-42.

Vaughn, M. G., Fu, Q., Beaver, K. M., DeLisi, M., Perron, B. E., \& Howard, M. O. (2010). Are personality disorders associated with social welfare burden in the United States? Journal of Personality Disorders, 24, 709-721.

Vaughn, M. G., Fu, Q., Bender, K., DeLisi, M., Beaver, K. M., Perron, B. E., \& Howard, M. O. (2010). Psychiatric correlates of bullying in the United States: Findings from a national sample. Psychiatric Quarterly, 81, 183-195.

Vaughn, M. G., Fu, Q., DeLisi, M., Beaver, K. M., Perron, B. E., \& Howard, M. O. (2010) Criminal victimization and comorbid substance use and psychiatric disorders in the United States: Results from the NESARC. Annals of Epidemiology, 20, 281-288.

Vaughn, M. G., Fu, Q. DeLisi, M., Beaver, K. M. Terrell, K., Perron, B. E. \& Howard, M. O. (2009). Correlates of cruelty to animals in the United States: Results from the National Epidemiologic Survey on Alcohol and Related Conditions. Journal of Psychiatric Research, 43, 1213-1218.

Vaughn, M. G., Fu, O., DeLisi, M., Wright, J. P., Beaver, K. M., Perron, B. E., \& Howard, M. O. (2010). Prevalence and correlates of fire-setting in the United States: Results from the National Epidemiologic Survey on Alcohol and Related Conditions. Comprehensive Psychiatry, 51, 217-223.

Wolfgang, M. E., Figlio, R. M., \& Sellin, T. (1972). Delinquency in a birth cohort. Chicago: University of Chicago Press. 